\title{
LINFOMA CUTÁNEO PRIMARIO DE CÉLULAS B, DEL TIPO DE LA PIERNA
}

\author{
Lina María Bonilla Jaramillo ${ }^{1}$, Jorge Enrique Calderón ${ }^{2}$, Juan Guillermo Chalela. ${ }^{3}$, María Isabel González \\ ${ }^{1}$ Médico, residente III año de Dermatología, Universidad Militar Nueva Granada, Bogotá, Colombia. \\ ${ }^{2}$ Médico, residente II año de Dermatología, Universidad Militar Nueva Granada, Bogotá, Colombia. \\ ${ }^{3}$ Médico, Internista, Dermatólogo, docente, Servicio de Dermatología, Hospital Militar Central, Bogotá, Colombia. \\ ${ }^{4}$ Médico, Dermatopatólogo, docente, Servicio de Dermatología, Hospital Militar Central, Bogotá, Colombia.
}

Recibido: Septiembre 1 de 2012 Aceptado: Diciembre 12 de 2012

\begin{abstract}
Resumen
El linfoma de células B del tipo de la pierna, es una neoplasia rara y agresiva, con características clínicas, morfológicas e inmunofenotípicas distintivas. Está clasificada dentro del grupo de linfomas cutáneos primarios de células $\mathrm{B}$ y se presenta en edades avanzadas, con predominio en mujeres y altas tasas de recurrencia.

Presentamos el caso de una mujer de 63 años de edad, con diagnóstico clínico e inmunofenotípico de linfoma cutáneo de células B del tipo de la pierna.
\end{abstract}

Palabras clave: linfoma cutáneo primario de células B, tipo de la pierna, inmunofenotipo, Rituximab.

\section{PRIMARY CUTANEOUS B CELL LYMPHOMA, LEG TYPE}

\begin{abstract}
Primary cutaneous $\mathrm{B}$ - cell lymphoma, leg type, is an uncommon and aggressive neoplasm with unique clinical features, morphology and immunophenotype. It is classified as a primary B-cell cutaneous lymphoma and it occurs in advanced age and women with high rates of recurrences.

We present the case of a 63-year-old woman, with clinical and immunophenotypic diagnosis of primary cutaneous B-cell lymphoma, leg type.
\end{abstract}

Key words: Primary cutaneous B-cell lymphoma, leg type, immunophenotype, Rituximab

\section{LINFOMA CUTÂNEO PRIMÁRIO DE CÉLULAS B, DO TIPO DA PERNA}

\section{Resumo}

\begin{abstract}
O linfoma de células B do tipo da perna é uma neoplasia rara e agressiva, com características clínicas, morfológicas e imunofenotípicas distintivas. Está classificado dentro do grupo de linfomas cutâneos primários de células $B$ e se apresenta em idades avançadas, com predomínio em mulheres e altas taxas de recorrência. Apresentamos o caso de uma mulher de 63 anos de idade, com diagnóstico clínico e inmunofenotípico de linfoma cutâneo de células B do tipo da perna.
\end{abstract}

Palavras chave: Linfoma cutâneo primário de células B, tipo da perna, inmunofenotipo, Rituximab.

\footnotetext{
Correspondencia: Departamento de Dermatología Servicio de Dermatología, Hospital Militar Central, Bogotá. Lina María Bonilla Email: lina.bonilla@gmail.com Teléfono: 3006149695
} 


\section{Introducción}

El linfoma de células B del tipo de la pierna, es una neoplasia rara y agresiva, clasificada en el año 2005 por la Organización Mundial de la Salud y la Organización Europea para la investigación y el tratamiento del cáncer, dentro del grupo de linfomas cutáneos primarios de células B.1

Se caracteriza por tener un pobre pronóstico, con alta expresión de $\mathrm{Bcl} 2$, la edad en la que se presenta es avanzada, la localización más frecuente es en la pierna y las tasas de supervivencia son 5 años del $41 \% .1$

\section{Caso clínico}

Paciente femenina, de 63 años de edad, natural y procedente de Bogotá, sin antecedentes patológicos relevantes.

Consulta por cuadro de 8 meses de evolución de aparición de nódulos de rápido crecimiento en cara medial y anterior de rodilla derecha.

En el momento del examen físico se presenta un tumor exofítico de 18 por $20 \mathrm{cms}$, con una ulceración central de 10 por $8 \mathrm{cms}$, secreción serohemática fétida y nódulos eritemato-violáceos adyacentes a la lesión principal (Figura 1 y 2 ).

Con impresión diagnóstica de linfoma cutáneo vs carcinoma escamocelular, se solicitan paraclínicos y realización de biopsia cutánea, hemograma con anemia microcítica hipocrómica, LDH elevada (1564), Rx, gamagrafía y RNM de rodilla, que reportaron masa dependiente de tejidos blandos con compromiso óseo de tibia y peroné.

La biopsia de piel muestra epidermis normal, con infiltrado difuso linfocitario dérmico, sin epidermotropismo e inmunohistoquímica con $\mathrm{Bcl} 2$ positivo, CD20 positivo, CD3 y Cd30 negativos. (Figura 3, 4, 5, 6).

Por su evolución, clínica y caracterización inmunohistoquímica, se realiza diagnóstico definitivo de Linfoma cutáneo primario de células $\mathrm{B}$, del tipo de la pierna. Se sugiere manejo con quimioterapia y Rituximab, tratamiento que la paciente no recibe, terminando finalmente, con amputación de la extremidad.

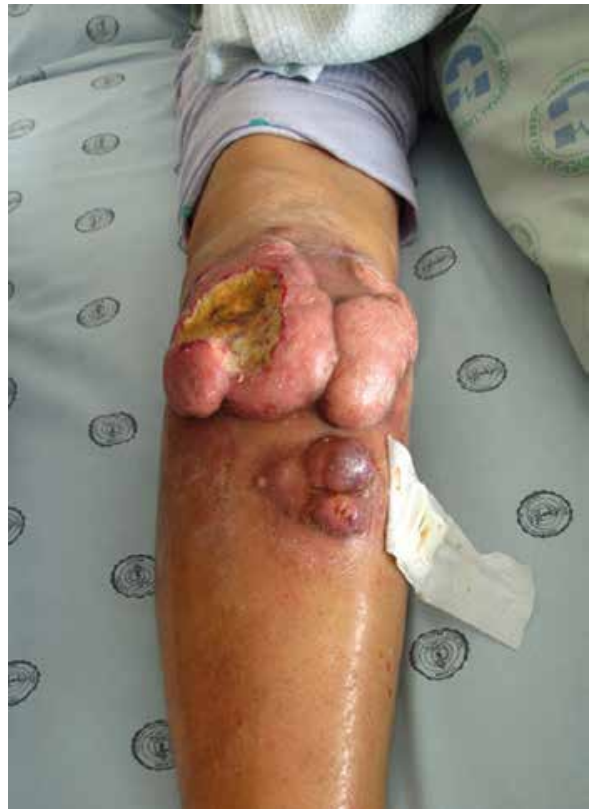

Figura 1. tumor exofítico de 18 por $20 \mathrm{cms}$ en rodilla derecha y nódulos eritemato-violáceos adyacentes a la lesión principal.

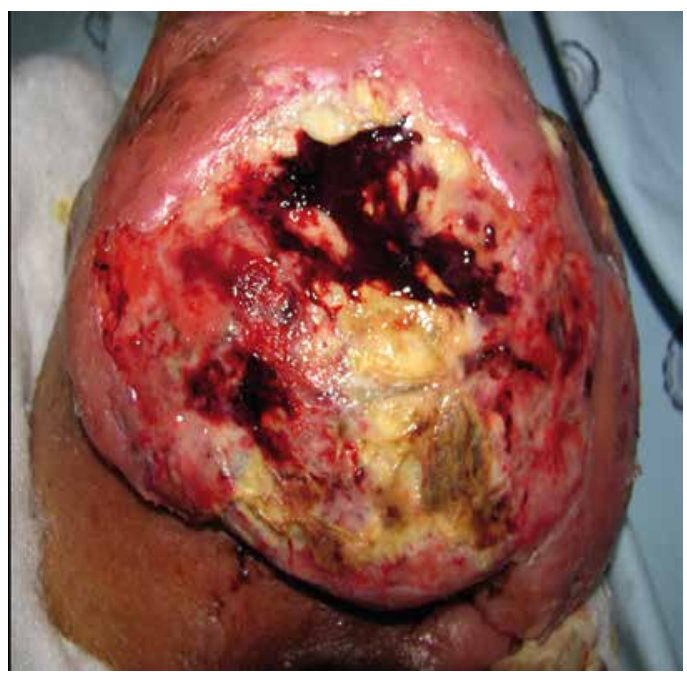

Figura 2. Con ulceración central de 10 por 8 cms y secreción serohemática fétida.

\section{Discusión}

El linfoma cutáneo primario de células $\mathrm{B}$, del tipo de la pierna, es una entidad recientemente descrita y junto con el linfoma de la zona marginal y el folículo céntrico, se clasifica dentro del grupo de linfomas cutáneos primarios de células $\mathrm{B}(1)$. 


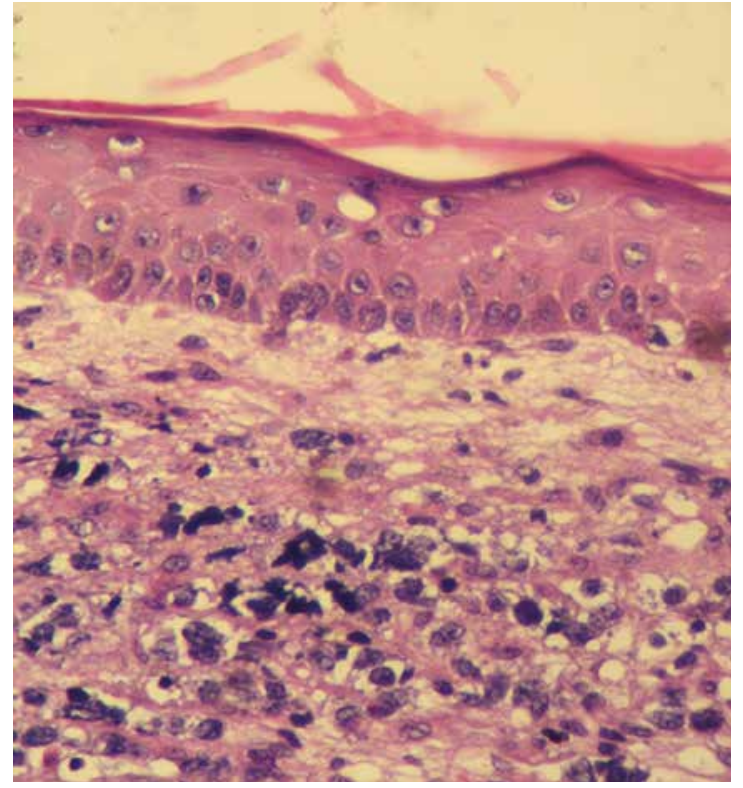

Figura 3. H-E: Ausencia de epidermotropismo, células pleomórficas, clonalidad linfocítica.

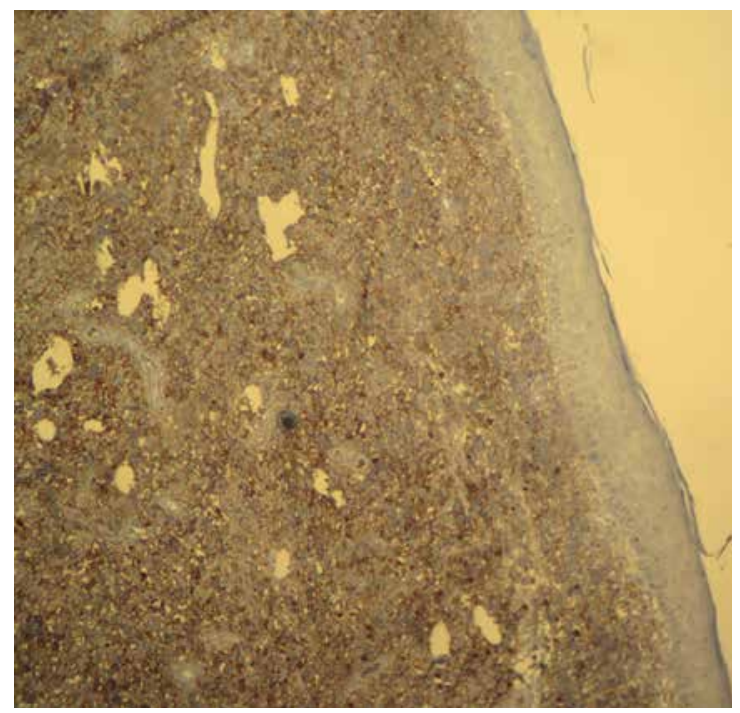

Figura 4. Inmunohistoquímica: $\mathrm{Bcl} 2$ positivo.

Los linfomas primarios de células $\mathrm{B}$, comprenden aproximadamente $20 \%$ de todos los linfomas cutáneos. Constituyen un grupo aparte de desórdenes linfoproliferativos, de presentación en la piel, sin evidencia de diseminación extracutánea al momento del diagnóstico (2).

Los linfomas de bajo grado como el linfoma foliculocéntrico y el de la zona marginal, usualmente se manifiestan en poblaciones de mediana edad, con una edad

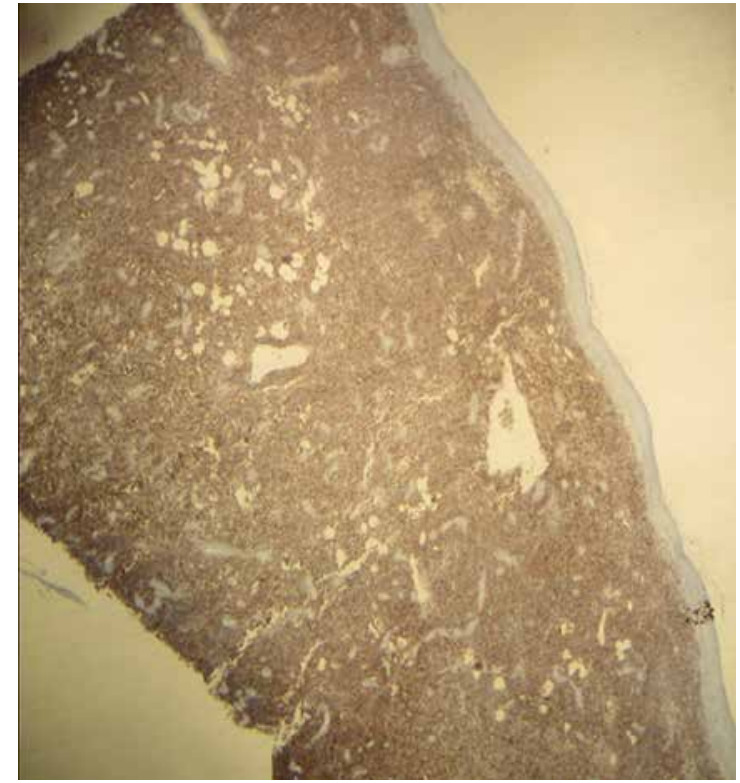

Figura 5. Inmunohistoquímica: CD 20 positivo.

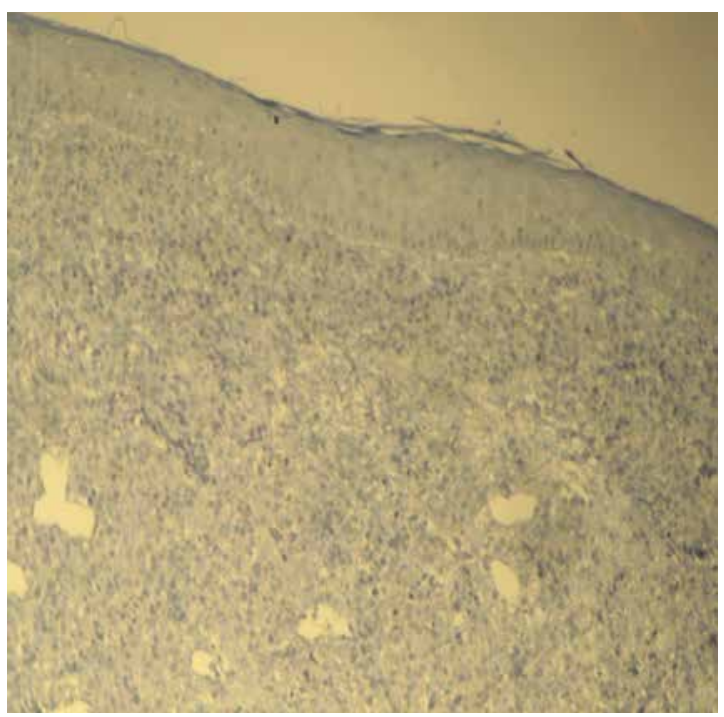

Figura 6. Inmunohistoquímica CD 30 negativo.

promedio de 53 a 58 años respectivamente. El linfoma de células $\mathrm{B}$, del tipo de la pierna, es una enfermedad de personas mayores, con edad promedio de 70 años. Con un radio hombre/mujer que varía entre 1:3 a 1:4 sin diferencia de raza o zona geográfica (3).

La patogénesis no está clara. Se cree que puede representar una respuesta linfoproliferativa a un estímulo antigénico en la piel. En Europa el linfoma de la zona marginal se ha asociado con la infección por Borrelia 
burgdorferi, pero esta asociación no se ha demostrado en Estados Unidos (4).

El linfoma de células B, del tipo de la pierna, se manifiesta como tumores rojo-azulados, placas violáceas o nódulos, en una o ambas piernas. Solo un $10-15 \%$, desarrollan lesiones en localizaciones diferentes a las extremidades inferiores (5).

A diferencia de los otros subtipos de linfomas cutáneos de células $\mathrm{B}$ primarios (folículocéntrico y de la zona marginal), estos tumores son más agresivos, de peor pronóstico, con diseminación frecuente a ganglios linfáticos y órganos. En grandes series, el compromiso extracutáneo se ha visto en el $43 \%$ de pacientes.

La sobrevida a 5 años varía entre un 36 a $55 \%$, comparado con un $95 \%$ para otros subtipos de linfomas primarios cutáneos $(2,3,6)$.

El diagnóstico se basa en la clínica, la histología, la inmunohistoquímica y el análisis genotípico en el especímen de la biopsia $(2,5)$. La patología muestra un infiltrado difuso de células $\mathrm{B}$, con ausencia de epidermotropismo y extensión al tejido celular subcutáneo. Las células neoplásicas expresan marcadores de células B (CD20, CD12, CD22, CD79a). Son fuertemente positivas para bcl-2. Bcl-6, MUM-1 y FOXP1 son positivos, mientras que CD 10 y CD 138 son negativos (7).

Dentro de los factores de mal pronóstico, se describen la localización en miembros inferiores, edad mayor de 75 años, predominio de células grandes en la histología y la expresión de la proteína $\mathrm{Bcl}-2$, con alta incidencia de recaídas, progresión en cortos períodos de tiempo y diseminación extracutánea más frecuente.

En cuanto al tratamiento, por su baja incidencia, son escasos los estudios terapéuticos randomizados y prospectivos (5).

La quimioterapia multiagente con rituximab (R-CHOP), seguida por radioterapia está recomendada como enfoque terapéutico inicial por las guías de la NCCN (National Comprehensive Cancer Network) $(2,6)$.

Tratamientos alternativos como radioterapia o Rituximab solos, se indican para pacientes cuya condición no permita el tratamiento con R-CHOP, pero estos regímenes tienen una baja tasa de respuesta completa y altas tasas de recaída. Un estudio retrospectivo con
Rituximab como monoterapia en 8 pacientes, observó respuesta del $75 \%$ después de 4 semanas de tratamiento, sin embargo, todos los pacientes presentaron recaída, con un promedio de sobrevida de 5.3 meses. Por otro lado, un estudio con 12 pacientes tratados con $\mathrm{R}-\mathrm{CHOP}$, demostró respuesta completa en $92 \%$ de pacientes (8).

\section{Conclusión:}

El linfoma de células B del tipo de la pierna, es una entidad recientemente reconocida como un subtipo clínico de linfoma cutáneo primario, por sus características clínicas, morfológicas e inmunofenotípicas. Tiene un comportamiento agresivo, con altas tasas de recaída y diseminación extracutánea. La quimioterapia multiagente en combinación con el Rituximab, constituye el tratamiento de primera línea y aunque en el caso aquí mostrado no se obtuvo un resultado terapéutico exitoso, esperamos que el conocimiento de esta entidad conduzca a mejores tratamientos y realización de estudios clínicos más grandes, que demuestren la eficacia de nuevos agentes.

\section{Bibliografía}

1. Lubomir Sokol, Mojdeh Naghashpour and L. Frank Glass. Primary Cutaneous B-Cell Lymphomas:Recent Advances in Diagnosis and Management. Cancer Control. 2012 Jul;19(3):236-44.

2. Senff NJ, Noordijk EM, Kim YH, et al. European Organization for Research and Treatment of Cancer and International Society for Cutaneous Lymphoma consensus recommendations for the management of cutaneous B-cell lymphomas. Blood. 2008;112(5):1600-1609.

3. Senff NJ, Hoefnagel JJ, Jansen PM, et al. Reclassification of 300 primary cutaneous B-cell lymphomas according to the new WHOEORTC classification for cutaneous lymphomas: comparison with previous classifications and identification of prognostic markers. J Clin Oncol. 2007;25(12):1581-1587.

4. Goodlad JR, Davidson MM, Hollowood K, et al. Primary cutaneous B-cell lymphoma and Borrelia burgdorferi infection in patients from the Highlands of Scotland. Am J Surg Pathol. 2000; 24(9):1279-1285.

5. Vibha Thomas, Robin Dobson and Robert Mennel. Primary cutaneous large B-cell lymphoma, leg type. Proc (Bayl Univ Med Cent) 2011; 24(4):350-353.

6. Grange F, Beylot-Barry M, Courville P, Maubec E, Bagot M, Vergier B,Souteyrand P, Machet L, Dalac S, Esteve E, Templier I, Delaporte E,Avril MF, Robert C, Dalle S, Laroche L, Delaunay M, Joly P, WechslerJ, Petrella T. Primary cutaneous diffuse large B-cell lymphoma, leg type:clinicopathologic features and prognostic analysis in 60 cases. Arch Dermatol 2007; 143(9):1144-1150.

7. Geelen FA, Vermeer MH, Meijer CJ, Van der Putte SC, Kerkhof E, Kluin PM, Willemze R. bcl-2 protein expression in primary cutaneous large B-cell lymphoma is site-related. J Clin Oncol 1998;16(6):2080-2085.

8. Guyot A, Ortonne N, Valeyrie-Allanore L, Bagot M. Combined treatment with rituximab and anthracycline-containing chemotherapy for primary cutaneous large B-cell lymphomas, leg type, in elderly patients. Arch Dermatol. 2010 Jan;146(1):89-91 